\title{
Molecular basis of parthenolide-dependent proapoptotic activity in cancer cells
}

\author{
Beata Pająk $^{1}$, Arkadiusz Orzechowski ${ }^{1,2}$, Barbara Gajkowska ${ }^{1}$ \\ ${ }^{1}$ Department of Cell Ultrastructure, Medical Research Centre, Polish Academy of Sciences, Warsaw, \\ Poland \\ ${ }^{2}$ Department of Physiological Sciences, Faculty of Veterinary Medicine, Warsaw University \\ of Life Sciences (SGGW), Warsaw, Poland
}

\begin{abstract}
This review outlines the molecular events that accompany the anti-tumor action of parthenolide (PN). Parthenolide (PN) is naturally derived compound, isolated from plant Tanacetum parthenium. PN has been previously shown to withdraw cells from cell cycle or to promote cell differentiation, and finally to induce programmed cell death. Recent advances in molecular biology indicate that this sesquiterpene lactone might evoke the above-mentioned effects by indirect action on genes. PN was shown to inhibit NF-кB- and STATs-mediated antiapoptotic gene transcription. On one hand, the proapoptotic activity of PN includes stimulation of intrinsic apoptotic pathway with the higher level of intracellular ROS and modifications of Bcl-2 family proteins (conformational changes of Bak and Bax, Bid cleavage). On the other hand, PN amplifies the apoptotic signal through the sensitization of cancer cells to extrinsic apoptosis, induced by TNF- $\alpha$. These effects are specific to tumor cells. Unique properties of PN make this agent a promising metabolic inhibitor to retard tumorigenesis and to suppress tumor growth.
\end{abstract}

Key words: Parthenolide - Apoptosis - Cancer cells

\section{Introduction}

The "immune escape", also known as immunoediting, is evolutionary developed ability of cancer cells to avoid elimination by the immune system [1-3]. The main strategies used, such as ignorance, impaired antigen presentation, expression of immunosuppressive factors and molecules, tolerance induction and apoptosis resistance allow tumor cells to grow and develop [3]. The current efforts are focused on the identification of the molecular mechanisms responsible for the inhibition of apoptotic signals and sensitization of cancer cells to natural cell death induction by metabolic inhibitors. Among various tested compounds also naturally derived substance such as parthenolide is considered as promising agent for future anti-cancer immunotherapy.

Correspondence: B. Pajak, Dept. of Cell Ultrastructure, Medical Research Centre, Polish Academy of Sciences, Pawinskiego Str. 5, 02-106 Warsaw, Poland; tel./fax.: (+4822)6685277, e-mail: bepaj@wp.pl

\section{Parthenolide - multifunctional naturally derived compound}

Sesquiterpene lactones are isolated from extracts of Mexican-Indian plants and have been widely used in indigenous medical practices, including treatment of migraines [4,5], inflammation [6], stomachache, toothache, menstrual irregularities, fever and rheumatoid arthritis [7]. Parthenolide is the principal component of sesquiterpene lactones present in medical plants such as feverfew (Tanacetum parthenium) [8]. PN contains an $\alpha-$ methylene- $\gamma$-lactone ring and an epoxide, which are able to interact readily with nucleophilic sites of biological molecules [9]. However, modern studies revealed that PN has also anti-microbial, anti-inflammatory and anticancer activities, which may depend on a wide range of $\mathrm{PN}$-stimulated intracellular signals $[10,11]$. The review describes the postulated molecular mechanism of PNmediated anti-tumor activity.

\section{Parthenolide inhibits NF- $\mathrm{KB}$ activation}

$\mathrm{NF}-\mathrm{\kappa B}$ transcription factor is a ubiquitously expressed transcription factor that regulates several vital func- 
tions i. e. it controls apoptosis, cell proliferation and differentiation and is a major player in the control of immune response and inflammation [12]. NF- $\mathrm{kB}$ is activated in response to several proapoptotic stimuli, such as TNF- $\alpha$, cytotoxic drugs [14], ionizing radiations [15] and oxidative stress [16]. In response to these stimuli, NF- $\mathrm{kB}$ translocates to the nucleus and regulates the expression of antiapoptotic genes. These antiapoptotic targets include those coding for TNF- $\alpha$ receptor associated factor 1 (TRAF1) and TRAF2, cIAPs, manganese superoxide dismutase (MnSOD), A20 and IEX-1L [15,17-19]. Moreover, NF-kB also controls the expression of Bfl-1/A1 and Bcl-xL, two antiapoptotic proteins from Bcl-2 family [20].

A number of experimental data indicate that the $\mathrm{NF}-\mathrm{KB}$ is involved in the development or progression of human cancers:

1. The v-rel oncogene of the reticuloendotheliosis virus $\mathrm{T}$ (Rev- $\mathrm{T}$ ) was the first member of the $\mathrm{Rel} / \mathrm{NF}-\kappa \mathrm{B}$ family to be discovered. It is a transforming gene and young chicken injected with the Rev-T virus develop aggressive lymphomas [21].

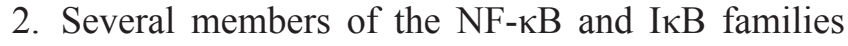
were derived from genes that are amplified or translocated in human caners. All these genetic events lead to increased NF- $\kappa B$ transcriptional activity, thus indicating that $\mathrm{NF}-\mathrm{kB}$ target genes might control important steps for cellular transformation or cancer progression. It was reported that $\mathrm{NF}-\kappa \mathrm{B}$ may control not only apoptosis and cell cycle progression, but also invasion and metastasis $[22,23]$.

3. More recently, NF- $\mathrm{kB}$ constitutive activity was observed in various tumors, such as Hodgkin's disease [24], colon cancer [25], breast cancer [26] and others.

The inhibition of NF-kB in cancer cells has become one of the major strategies in anticancer therapy. The well documented inhibitor of this transcription factor is parthenolide. According to numerous data $\mathrm{PN}$ is the inhibitor of IkB kinases complex (IKC), with the sustained cytoplasmic retention of NF- $\mathrm{KB}$. Multisubunit IKC complex consists of a two proteins IKK $\alpha$ and IKK $\beta$ [27]. IKK $\beta$ is essential modulator/IKK $\gamma$ complex-associated protein attached to NF- $\kappa B$, which also binds to NF- $\kappa \mathrm{B}$-inducing kinase (NIK) [28]. Also MAP3 kinase NIK was identified as a direct IKK activator [29]. Similarly, MEKK1 was found to interact and activate both of IKKs [30]. There are contradictory data concerning the direct target of $\mathrm{PN}$ action in IKC complex. Kwok et al. [31] synthesized the PN affinity reagent and showed its direct binding to IKK $\beta$, the kinase subunit known to play a critical role in cytokine-mediated signaling. Mutation of cysteine 179 in the activation loop of IKK $\beta$ abolished sensitivity towards PN. Moreover, the authors showed that PN's in vitro and in vivo anti-inflammatory activity is mediated through the $\alpha$-methylene $\gamma$-lactone moiety shared by other sesquiterpene lactones. Additionally, Saadane et al. [32] found that the inhibition of IKK $\beta$ resulted in stabilization of cytoplasmic IKK $\alpha$, which in turn leads to inhibition of NF- $\mathrm{kB}$ translocation. In contrast, Hehner et al. [28] speculated that PN interferes with IKC component that is necessary for the sequential transmission of signals leading to the activation of both IKKs. Since the IKC is non-functional in the absence of NK$\kappa \mathrm{B}$ essential modulator/IKK $\gamma$, this latter protein was the potential candidate for the inhibitory activity of parthenolide. Moreover, in all cases, the PN administration blocked DNA-binding of NF- $\mathrm{kB}$. Consequently, lack of NF-KB activity render cancer cells prone to undergo apoptosis or became sensitized to cytokine- and anti-cancer drug-induced cell death [33-36].

\section{Parthenolide suppresses STATs activity}

The signal transducer and activator of transcription (STAT) proteins are extracellular ligand-responsive transcription factors that mediate broadly diverse biological functions, such as cell proliferation, transformation, apoptosis, differentiation, fetal development, inflammation and immune response [37]. At present, seven STATs have been identified in mammals: STAT1, STAT-2, STAT-3, STAT-4, STAT-5a, STAT-5b and STAT-6. The cytokine or growth factor stimulation resulted in the tyrosine phosphorylation of STATs, followed by dimerization and the subsequent gene regulation via their direct binding to the DNA consensuses. Many tyrosine kinases, including JAKs (Janus kinases), TYKs (tyrosine kinases), RTKs (receptor tyrosine kinases) and other non-RTKs can phosphorylate STATs. In normal cells, STAT tyrosine phosphorylation is transient, lasting from 30 minutes to several hours. However, in numerous cancer-derived cell lines or in a primary tumors, STATs, especially STAT-3, are persistently tyrosine phosphorylated either as a consequence of deregulated positive effectors of STATs activation, such as upstream tyrosine kinases (JAK, TYK) or repression of negative regulators of STATs phosphorylation, e.g. phosphatases, suppressors of cytokine signaling (SOCS) or protein inhibitors of activated STATs (PIAS) [38]. Constitutively activated STATs have been observed for example in leukemia, multiple myeloma, breast cancer, prostate cancer, colorectal cancer, hepatocellular carcinoma, skin cancer and others [39-43]. The products of STATs-regulated gene transcription, including Bcl-xL and survivin [44] allow cancer cells to proliferate and to inhibit apoptosis. Therefore, the compounds having property to inhibit STATs in cancer cells have been intensively tested. Among them, the strong candidate for future anti-cancer therapy is parthenolide. 
According to Sobota et al. [45], in human hepatocarcinoma HepG2 cells STAT-3 activation is the consequence of IL-6-type cytokine action (IL-6, LIF, OSM, IL-11, CT-1 and CNTF). The IL-6 type cytokines signaling pathway leads to activation in HepG2 cells of liver-derived acute phase proteins (APPs) such as ACT ( $\alpha_{1}$-antichymotrypsin) [46]. The presence of parthenolide efficiently inhibited the IL-6induced up-regulation of ACT mRNA. Further analysis revealed that parthenolide effect was achieved by blocking of STAT-3 and STAT-1 binding to the regulatory elements in DNA. Furthermore, PN inhibited binding of STAT-3 due to the inhibition of OSMinduced phosphorylation of tyrosine 705 residue. This prevented STAT-3 dimerization, a step required for its translocation to the nucleus and subsequent gene activation. The authors hypothesized that PN inhibits JAKs through conjugation with their SH groups. This supposition supported the results obtained in the presence of $\beta$-mercaptoethanol ( $\beta \mathrm{ME}$ ) since this reducing agent restored responsiveness to cytokines most likely by preventing interaction of parthenolide with $\mathrm{SH}$ groups of target proteins [45].

Another cytokine which mediates its signal through STATs is IL-4. In IL-4-stimulated endothelial cells the STAT-6-dependent gene transcription occurs [47]. However, the parthenolide administration inhibited STAT-6 DNA-binding activity in IL-4-treated cells and inhibited the IL-4-driven activation of a luciferase reporter gene under the control of STAT-6-responsive elements. Interestingly, the authors reported that PN did not interfere with the immediate IL-4-induced phosphorylation of endothelial STAT-6 on its tyrosine residue 641 and with tyrosine phosphorylation of the adapter molecule, JAK2 - both processes are obligatory for dimerization and nuclear translocation of STAT6. It is possible that the target for PN in the JAK/STAT pathway is cell specific. Finally, the ability of parthenolide to inhibit STATs action was confirmed by Legendre et al. [48], who used PN as an experimental inhibitor of STAT-1 and STAT-3 in articular chondrocytes.

\section{The role of $\mathrm{JNK}$ in parthenolide-mediated regulation of cell death}

JNK is one of the MAPK (mitogen activated protein kinases) group, together with ERKs, p38 and ERK5 [49]. All MAPKs are activated by dual phosphorylation on threonine and tyrosine motifs within the activation loop. Once activated, they translocate to the nucleus and phosphorylate target transcription factors, such as c-Jun. One of the potent JNK pathway activator is UV. It is rather controversial in regard to the exact role of JNK in UV-mediated apoptosis. For instance, JNK has been shown to be required for UV- induced apoptotic cell death in mouse embryonic fibroblast [50], while others demonstrated the antiapoptotic role of JNK in UV-induced apoptosis [51].

Interestingly, Won et al. [52] showed that parthenolide inhibited JNK activation and led to sensitization of JB6 murine epidermal cells to UVB-induced apoptosis, suggesting antiapoptotic role of JNK in this system. Moreover, PN appeared as a potent inhibitor of p38 activation, what also corresponded with sensitization to UVB-induced cell death. Eventually, the PNelicited sensitization of JB6 cells to UVB-induced apoptosis was twice as strong as with the individual JNK and p38 inhibitor. The opposite results concerning the influence of parthenolide on JNK activity were demonstrated by Zhang et al. [35]. The authors examined the TNF- $\alpha$-dependent activation of JNK in human nasopharyngeal carcinoma CNE1 cell line. They found that PN sensitizes CNE1 cells to TNF- $\alpha$ induced apoptosis. The observed effect was the consequence of described above PN-mediated inhibition of TNF- $\alpha$-induced NF- $\kappa B$ activation. However, the authors proposed novel mechanism, based on limited assembly of IKK complex with TNF-R1. On the other hand, the PN and JNK interaction has been explained. For the first time, Zhang et al. [35] described the duration of JNK activation in TNF- $\alpha$-exposed cells. In accordance with previous studies published by Tang et al. [53] and Varfolomeev et al. [54] the authors concluded that sustained JNK activation resulted from $\mathrm{NF}-\kappa \mathrm{B}$ inhibition. More important, based on the observations that $\mathrm{PN}$ alone induces a certain degree of JNK activation it appeared that PN itself activates JNK activation through a TNF- $\alpha$ receptor independent pathway. Similar observations of PN-mediated prolonged JNK activity were described by Shanmugam et al. [55] in prostate cancer cells.

However, despite of analogous results the final molecular mechanism for the observed JNK activation by PN has not been described yet. It should be emphasized that differential influence of PN on JNK activity in murine epithelial cells vs. cancer cells might be useful in clinical practice. Based on the literature data, it seems that in normal cells PN protects cells from apoptosis, whereas in cancer cells it supports immune system- or anti-cancer drug-induced cell death.

\section{Oxidative stress-mediated parthenolide action and its effect on mitochondrial activity}

Oxidative stress refers to the cellular status with enhanced production of intracellular reactive oxygen species (ROS) and/or impaired function of the cellular anti-oxidant defense system [56]. The intracellular redox status is a precise balance between oxidative stress and endogenous thiol buffering system. It includes a great deal of non-protein low-molecular 
weight molecules, such as glutathione (GSH), as well as several protein thiols, such as thioredoxin. It has been shown that the intracellular redox status play an important role in survival and cell death [57]. Many cancer therapeutics are apoptosis inducers as they can disrupt the redox balance by depleting the intracellular thiol buffer system through the extrusion [58] or redistribution of GSH. The unbalanced intracellular redox state thus triggers the downstream cellular events, such as alternation of mitochondrial function and cell signaling pathways, which all lead to apoptotic cell death [35].

According to several studies, parthenolide modulates redox homeostasis and enables progression into cell death. In colorectal cancer cells PN depletes intracellular GSH and protein thiols in a time and dosedependent manner [35]. Moreover, PN significantly enhanced the intracellular ROS and cytosolic calcium levels, and induced ER stress. Pretreatment of colorectal cancer cells with $N$-acetyl- $L$-cystein (NAC) diminished intracellular ROS and calcium levels and protected cells from PN-induced apoptosis. Moreover, the use of GSH synthesis inhibitor - buthionine sulfoximine (BSO), caused a further depletion (more than $50 \%$ ) of GSH and sensitized cells to PN-induced apoptosis. The finding that BSO alone does not induce apoptosis suggests that the intracellular GSH plays a critical role in parthenolide-induced apoptosis. This supposition is supported by the results published by Wen et al. [59], who demonstrated that parthenolide action is due to the glutathione depletion. Bearing in mind that mitochondrial respiratory chain is the major production site of intracellular ROS both mitochondrial integrity and its proper function are essential and are often subject to the adverse effects of oxidative stress. Zhang et al. [60] examined the influence of PN on mitochondria function in colorectal cancer cells. They found that PN activated caspases, dissipated the mitochondrial membrane potential and released the mitochondrial proapoptotic proteins, such as cytochrome $c$ and Smac/DIABLO. The confirmation of mitochondrial (intrinsic) cell death pathway induction was the caspase-8-processed cleavage of Bid to tBid protein after $\mathrm{PN}$ administration. tBid has proapoptotic activity closely related to other Bcl-2 family members. There are two possible ways of tBidinduced mitochondrial dysfunction: translocation and oligomerization of tBid on mitochondrial membrane, which causes the release of cytochrome $c$ [61], or activates other proteins, such as Bax and Bak [62]. In colorectal cancer cells the conformational changes of Bax and up-regulated level of Bak proteins were observed. All these changes of proapoptotic Bcl-2 family members lead to mitochondrial dysfunction and apoptosis induction. The PN-mediated apoptosis and the role of oxidative stress were also evaluated by Wang et al.
[63]. In multiple myeloma cells (MM) PN was able to initiate apoptosis. The detailed analysis showed that the PN susceptibility was determined by the catalase activity, the potent cellular $\mathrm{H} 2 \mathrm{O} 2$ scavenger enzyme. The low level of catalase activity was detected in MM cell line, while the high activity of this enzyme in normal cells protected cells from PN-induced apoptosis. Contradictory to previous results, Wang et al. [63] did not observe any changes in Bcl-xL or JNK action. Next evidence for ROS-dependent PN action was demonstrated by Zunino et al. [64] in pre-B acute lymphoblastic leukemia (ALL) cells. In ALL cells parthenolide induced rapid apoptotic cell death distinguished by the loss of nuclear DNA, externalization of cell membrane phosphatidylserine and depolarization of mitochondrial membranes. Using reactive oxygen species-specific dyes an increase in nitric oxide and superoxide anion radical was detected after 4 hours exposure to PN. In two, from all tested MM cell lines, also the elevated level of hypochloride anion was detected [64].

It is clear that $\mathrm{PN}$ affects several cellular pathways and the modulation of redox state seems to be the efficient treatment for anti-cancer therapy.

\section{Parthenolide specifically affects malignant cells}

Studies of intensive immunotherapy revealed several metabolic inhibitors, such as cycloheximide [65], actinomycin D [66], anisomycin, harringtonine [67] and other metabolic inhibitors, which are able to modulate the resistance of various cancer cells to cytokineinduced cell death. However, the clinical use of several tumor cell death promoting agents is limited, because they act non-specifically and are often cytotoxic. In turn, due to its low toxicity PN seems to be the ideal agent in the future anti-cancer immunotherapy. Described above PN-mediated effects on JNK activity could be both pro- or antiapoptotic. It should be emphasized that PN action in normal cells augments cells viability and protects them from UVB[52] or ROS-induced apoptosis $[59,63,68]$. In contrast, PN is toxic to abnormal cells. The good example of dual PN activity was presented by Guzman et al. [69]. It was shown that PN preferentially targets leukemia cells while sparing normal hematopoetic cells. The viability of acute myelogenous leukemia cells (AML) and chronic myelogenous leukemia cells was greatly reduced after PN administration. It was estimated, that viability was more than 10 -fold less that of the normal hematopoetic controls. Noteworthy, the analogous analysis concerning the progenitor and stem cells (myeloid or lymphoid lineages) confirmed lack of PN cytotoxic effect on normal cells and specific anti-cancer action. 


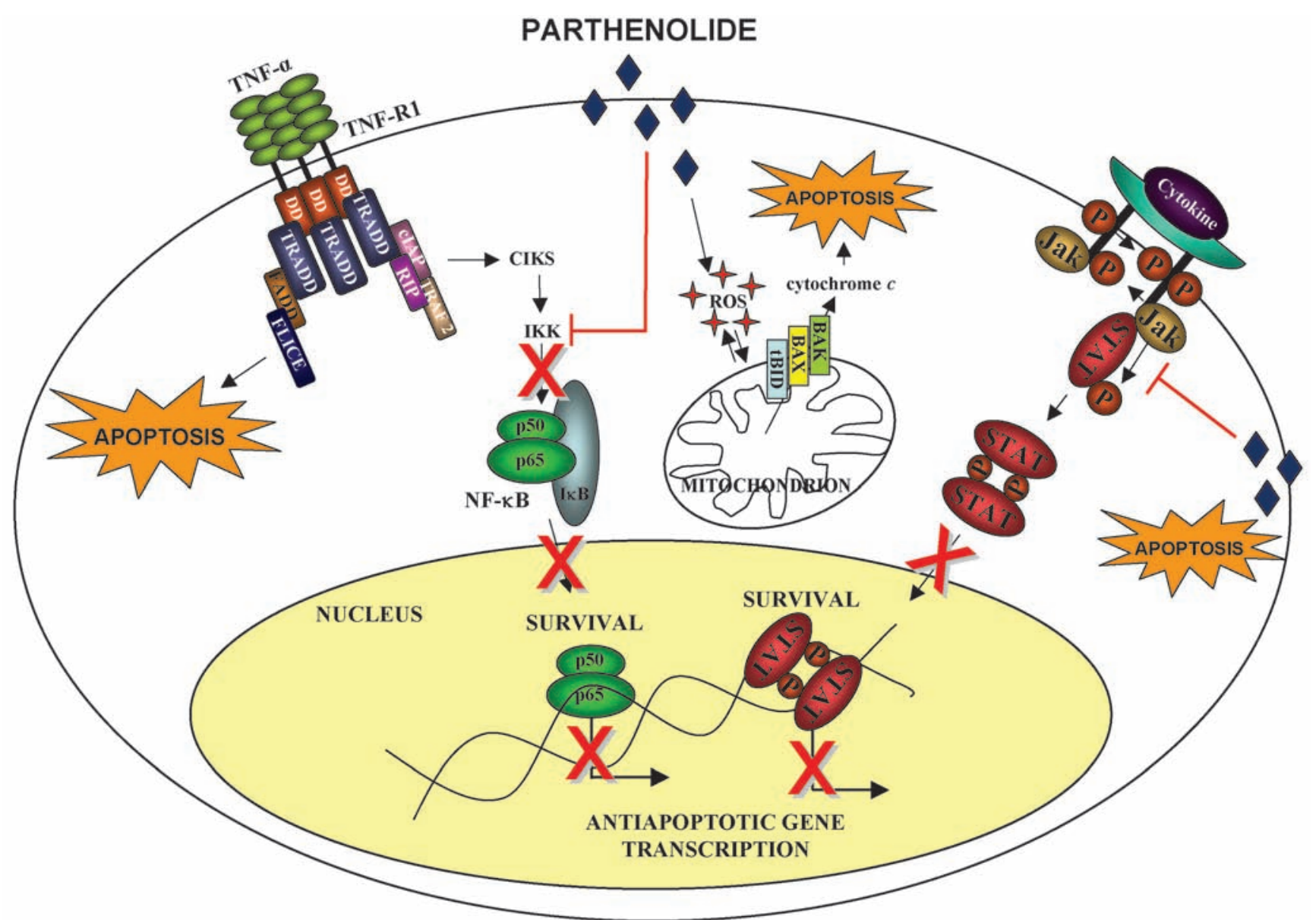

Fig. 1. Tentative model for the mechanisms of parthenolide-mediated apoptosis induction. Parthenolide-dependent inhibition of NF- $\mathrm{B}$ and STATs transcriptional activity results in the down-regulation of antiapoptotic gene transcription. As a consequence the cancer cells become sensitive to induction of extrinsic apoptosis. Additionally, the PN-induced oxidative stress mediates the mitochondrial dysfunction and it initiates the intrinsic apoptosis. These intracellular changes facilitate apoptosis of cancer cells.

\section{Summary}

Herein, the various molecular mechanisms of proapoptotic action of sesquiterpene lactone parthenolide on cancer cells were described. On the transcriptional level, PN affects both NF-kB and STATs transcription factors activity. The up- or down-regulation of specific genes results in the elimination of antiapoptotic proteins such as survivin, cIAP, Bcl-xL and/or additional ROS generation and intrinsic apoptotic pathway induction (Fig. 1). All these cellular changes help to restore the natural processes of cancer cell deletion. Additionally, the presented in vitro and in vivo studies showed that parthenolide specifically affects malignant but is harmless to normal cells. Thus, parthenolide should be seriously considered as potent candidate to facilitate anticancer treatment or an adjuvant in novel immunotherapy.

Acknowledgements: Beata Pajak dedicates this paper to Prof. Pawel Sysa (Department of Morphological Sciences, Faculty of Veterinary Medicine, Warsaw University of Life Sciences) for his support, kindness and encouragement.

\section{References}

[1] Hahne M, Rimoldi D, Schroter M, Romero P, Schreier M, French LE, Schneider P, Bornand T, Fontana A, Lienard D, Cerottini J, Tschopp J. Melanoma cells expression of Fas(Apo-1/CD 95) ligand: implications for tumor immune escape. Science. 1996;274:1363-1366.

[2] Medema JP, de Jong J, van Hall T, Melief CJ, Offringa R. Immune escape of tumors in vivo by expression of cellular FLICE-inhibitory protein. J Exp Med. 1999;190:1033-1038.

[3] Igney FH, Krammer PH. Immune escape of tumors: apoptosis resistance and counterattack. J Leukoc Biol. 2002;71:907920.

[4] Johnson ES, Kadam NP, Hylands DM, Hylands PJ. Efficacy of feverfew as prophylactic treatment for migraine. $\mathrm{Br} \mathrm{Med} \mathrm{J}$. 1985,31:569-573.

[5] Biggs MJ, Johnson ES, Persaud NP, Rateliffe DM. Platelet aggregation in patients using feverfew for migraine. Lancet. 1982,2:776.

[ 6] Hall ICH, Lee KH, Starnes CO, Sumida Y, Wu RY, Waddell TG, Cochran JW, Gerhart KG. Anti-inflammatory activity of sesquiterpene lactones and related compounds. J Pharm Sci. 1979,68:537-542.

[7] Jain NK, Kulkarni SK. Antinociceptive and anti-inflammatory effects of Tanacetum parthenium L. extracts in mice and rats. J Ethnopharm. 1999;68:251-259. 
[ 8] Knight DW. Feverfew, chemistry and biological activity. Nat Prod Rep. 1995;12:271-276.

[9] Bork PM, Schmitz ML, Kuhnt M, Escher C, Heinrich M. Sesquiterpene lactone containing Mexican Indian medical plants and pure sesquiterpene lactones as potent inhibitors of transcription factor NF-KB. FEBS Lett. 1997,402:85-90.

[10] Zhang S, Ong CN, Shen HM. Critical roles of intracellular thiols and calcium in parthenolide-induced apoptosis in human colorectal cancer cells. Cancer Lett. 2004;208:143153.

[11] Woynarowski JM, Konopa J. Inhibition of DNA biosynthesis in HeLa cells by cytotoxic and antitumor sesquiterpene lactones. Mol Pharmacol. 1981;19:97-102.

[12] Bours V, Bentires-Alj M, Hellin AC, Viatour P, Robe P, Delhalle S, Benoit V, Merville MP. Nuclear factor- B, cancer and apoptosis. Biochem Pharmacol. 2000;60:1085-1090.

[13] Shishodia S, Aggarwal BB. Nuclear factor-kappa activation: a question of life or death. J Biochem Mol Biol. 2002;35:28-40.

[14] Trubiani O, Salvolini E, Vignini A, D'Arcangelo C, Di Primo R, Mazzanti L. NF-kappaB and NOS may play a role in human RPMI-8402 cell apoptosis. Cell Biol Int. 2005;29:529536.

[15] Fan M, Ahmed KM, Coleman MC, Spitz DR, Li JJ. Nuclear factor-kappa B and manganese superoxide dismutase mediate adaptive radioresistance in low-dose irradiated mouse skin epithelial cells. Cancer Res. 2007;67:3220-3228.

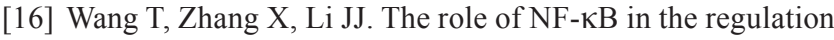
of cell stress responses. Int Immunopharmacol. 2002;2: 1509-1520.

[17] Munzert G, Kirchner D, Stobbe H, Bergman L, Schmid RM, Dohner H, Heimpel H. Tumor necrosis factor receptor-associated factor 1 gene overexpression in B-cell chronic lymphocytic leukemia: analysis of NF-kappaB/Rel-regulated inhibitors of apoptosis. Blood. 2002;100:3749-3756.

[18] Storz P, Doppler H, Ferran C Grey ST, Toker A. Functional dichotomy of A20 in apoptotic and necrotic cell death Biochem J. 2005;387:47-55.

[19] Osawa Y, Nagaki M, Banno Y, Brenner DA, Nozawa Y, Moriwaki H, Nakashima S. Expression of the NF-kappaB target gene X-ray-inducible immediate early response factor 1 short enhances TNF-alpha-induced hepatocyte apoptosis by inhibiting Akt activation. J Immunol. 2003;170:4053-4060.

[20] Khoshnan A, Tindell C, Laux I, Bae D, Bennett B, Nel AE. The NF-kappaB cascade is important in in $\mathrm{Bcl}-\mathrm{xL}$ expression and for the anti-apoptotic effects of the $\mathrm{CD} 28$ receptor in primary human CD4+ lymphocytes. J Immunol. 2000;165: 1743-1754.

[21] Gilmore TD, Temin HM. Different localization of the product of the v-rel oncogene in chicken fibroblasts and spleen cells correlates with transforming by REV-T. Cell. 1986;44:791800.

[22] Wieckowski E, Atarashi Y, Stanson J, Sato TA, Whiteside TL. FAP-1 mediated activation of NF-kappaB induces resistance of head and neck cancer to Fas-induced apoptosis. $J$ Cell Biochem. 2007;100:16-28.

[23] Montagut C, Tusquest I, Ferrer B, Corominas JM, Bllosillo B, Campas C, Suarez M, Fabregat X, Campo E, Gascon P, Serrano S, Fernandez PL, Rovira A, Albanell J. Activation of nuclear factor kappaB is linked to resistance to neoadjuvant chemotherapy in breast cancer patients. Endocr Relat Cancer. 2006;13:607-616

[24] Horie R, Watanabe T. The biological basis of Hodgin's lymphoma. Drug News Perspect. 2003;16:649-656.

[25] Braeuer SJ, Bunker C, Mohr A, Zwacka RM. Constitutively activated nuclear factor-kappa $\mathrm{B}$, but not induced NF- $\mathrm{KB}$, leads to TRAIL resistance by up-regulation of X-linked inhibitor of apoptosis protein in human cancer cells. Mol Cancer Res. 2006;4:715-728.
[26] Wu JT, Kral JG. The NF-kappaB/IkappaB signaling system: a molecular target in breast cancer therapy. J Surg Res. 2005; 123:158-169.

[27] Ghosh S, May MJ, Kopp EB. NF-кB and Rel proteins: evolutionary conserved mediators of immune responses. Annu Rev Immunol. 1998;16:225.

[28] Hehner SP, Hofmann TG, Droge W, Schmitz ML. The antiinflammatory sesquiterpene lactone parthenolide inhibits NF-

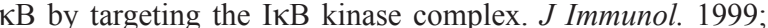
163:5617-5623.

[29] Malinin NL, Boldin MP, Kovalenko AV, Wallach D. MAP3Krelated kinase involved in the NF-KB induction by TNF, CD95 and IL-1. Nature. 1997;385:540.

[30] Lee FS, Peters RT, Dang LC, Maniatis T. MEKK1 activates both IкB kinase $\alpha$ and IкB kinase $\beta$. Proc Natl Acad Sci USA. 1998;95:9319.

[31] Kwok BH, Koh B, Ndubuisi MI, Elofsson M, Crews CM. The anti-inflammatory natural product parthenolide from the medical herb Feverfew directly binds to and inhibits IkappaB kinase. J Chem Biol. 2001;8:759-766.

[32] Saadane A, Masters S, DiDonato J, Li J, Berger M. Parthenolide inhibits IkappaB kinase, NF- $\mathrm{KB}$ activation and inflammatory response in cystic fibrosis cells in mice. Am J Respir Cell Mol Biol. 2007,36:728-36.

[33] Kim JH, Liu L, Lee SO, Kim YT, You KR, Kim DG. Susceptibility of cholangiocarcnoma cells to parthenolide-induced apoptosis. Cancer Res. 2005;65:6312-6320.

[34] Sweeney CJ, Mehrotra S, Sadaria MR, Kumar S, Shortle NH, Roman Y, Sheridan C, Campbell RA, Murry DJ, Badve S, Nakshatri $\mathrm{H}$. The sesquiterpene lactone parthenolide in combination with docetaxel reduces metastasis and improves survival in a xenograft model of breast cancer. Mol Cancer Ther. 2005;4:1004-1012.

[35] Zhang S, Lin ZN, Yang CF, Shi X, Ong CN, Shen HM. Supressed NF-KB and sustained JNK activation contribute to the sensitization effect of parthenolide to TNF- $\alpha$-induced apoptosis in human cancer cells. Carcinogenesis. 2004,25:1-9.

[36] Oka D, Nishimura K, Shiba M, Nakai Y, Arai Y, Nakayama $\mathrm{M}$, Takayama $\mathrm{H}$, Inoue $\mathrm{H}$, Okuyama A, Nonomura $\mathrm{N}$. Sesquiterpene lactone parthenolide suppresses tumor growth in a xenograft model of renal cell carcinoma by inhibiting the activation of NF-kappaB. Int J Cancer. 2007,120:2576-2581.

[37] Meyer T, Vinkemeier U. STAT nuclear translocation: potential for pharmacological intervention. Expert Opin Ther Targets. 2007;11:1355-1365.

[38] Bromberg J. Stat proteins and oncogenesis. J Clin Invest. 2002;109:1139-1142.

[39] Lee TK, Man K, Poon RT, Lo CM, Yuen AP, Ng IO, Ng KT, Leonard W, Fan ST. Signal transducers and activators of transcription $5 \mathrm{~b}$ activation enhances hepatocellular carcinoma aggressiveness through induction of epithelial-mesenchymal transition. Cancer Res. 2006;66:9948-9956.

[40] Ma XT, Wang S, Ye YJ, Du RY, Cui ZR, Somsouk M. Constitutive activation of Stat 3 signaling pathway in human colorectal carcinoma. World J Gastroenterol. 2004;10:1569-1573.

[41] Pedranzini L, Leitch A, Bromberg J. Stat3 is required for the development of skin cancer. J Clin Invest. 2004;114:619-622.

[42] Sheen-Chen SM, huang CC, Tang RP, Yang CH, Chou FF, Eng HL. Signal transducer and activator of transcription 1 in breast cancer: analysis with tissue microarray. Anticancer Res. 2007;27:2481-2486.

[43] Ferrajoli A, Faderl S, Ravandi F, Estrov Z. The JAK-STAT pathway: a therapeutic target in hematological malignancies. Curr Cancer Drug Targets. 2006;6:671-679.

[44] Kanda N, Seno H, Konda Y, Marusawa H, Kanai M, Nakajima T, Kawashima T, Nanakin A, Sawabu T, Uenoyama Y, Sekikawa A, Kawada M, Suzuki K, Kayahara T, Fukui H, Sawada M, Chiba T. STAT3 is constitutively activated and 
supports cell survival in association with survivin expression in gastric cancer cells. Oncogene. 2004;23:4921-4929.

[45] Sobota R, Szwed M, Kasza A, Bugno M, Kordula T. Parthenolide inhibits activation of signal transducers and activators of transcription (STATs) induced by cytokines of the IL-6 family. Biochem Biophys Res Commun. 2000;267:329-333.

[46] Knowles BB, Howe CC, Aden DP. Human hepatocellular carcinoma cell lines secrete the major plasma proteins and hepatitis B surface antigen. Science. 1980;209:497-499.

[47] Schnyder B, Schnyder-Candrian S, Panski A, Bommel H, Heim M, Duschl A, Moser R. Phytochemical inhibition of interleukin-4 activated Stat6 and expression of VCAM-1. Biochem Biophys Res Commun. 2002;292:841-847.

[48] Legendre F, Dudhia J Pujol JP, Bogdanowicz P. JAK/STAT but not ERK1/ERK2 pathway mediates interleukin (IL)-6/soluble IL-6R down-regulation of type II collagen, aggrecan core and link protein transcription in articular chondrocytes. Association with a down-regulation of SOX9 expression. $J$ Biol Chem. 2003; 278:2903-2912.

[49] Chang J, Karin M. Mammalian MAP kinase signaling cascades. Nature. 2001,410:37-40.

[50] Tournier C, Hess P, Yang DD, Xu J, Turner TK, Nimnual A, Bar-Sagi D, Jones SN, Flavell RA, Davis RJ. Requirement of JNK for stress-induced activation of the cytochrome c-mediated death pathway. Science. 2000;288:870-874.

[51] Chen W, Bowden GT. Role of p38 mitogen-activated protein kinases in ultraviolet-B irradiation-induced activator protein 1 activation in human keratinocytes. Mol Carcinog. 2000;28: 196-202.

[52] Won YK, Ong CN, Shi X, Shen HM. Chemopreventive activity of parthenolide against UVB-induced skin cancer and its mechanisms. Carcinogenesis. 2004;25:1449-1458.

[53] Tang G, Minemoto Y, Dibling B, Purcell NH, Li Z, Karin M, Lin A. Inhibition of JNK activation through NF-kappaB target genes. Nature. 2001;414:313-317.

[54] Varfolomeev EE, Ashkenazi A. Tumor necrosis factor: an apoptosis JuNKie? Cell. 2004;116:491-497.

[55] Shanmugam R, Jayaprakasan V, Gokmen-Polar Y, Kelich S, Miller KD, Yip-Schneider M, Cheng L, Bhat-Nakshatri P, Siedge GW, Nakshatri H, Zheng QH, Miller MA, DeGrado T, Hutchins GD, Sweeney CJ. Restoring chemotherapy and hormone therapy sensitivity by parthenolide in a xenograft hormone refractory prostate cancer model. Prostate. 2006;66: 1498-1511.

[56] Buttke TM, Sandstrom PA. Oxidative stress as a mediator of apoptosis. Immunol Today. 1994;15:7-10.

[57] Hampton MB, Orrenius S. Redox regulation of apoptotic cell death. Biofactors. 1998;8:1-5.

[58] Ghibelli I, Coppola S, Rotilio G, Lafavia E, Maresca V, Ciriolo MR. Non-oxidative loss of glutathione in apoptosis via
GSH extrusion. Biochem Biophys Res Commun. 1995;216: 313-320.

[59] Wen J, You KR, Lee SY, Song CH, Kim DG. Oxidative stressmediated apoptosis. J Biol Chem. 2002;277:38954-38964.

[60] Zhang S, Ong CN, Shen HM. Involvement of proapoptotic bcl-2 family members in parthenolide-induced mitochondrial dysfunction and apoptosis. Cancer Lett. 2004;211:175-188.

[61] Li H, Zhu H, xu CJ, Yuan J. Cleavage of BID by caspase 8 mediates the mitochondrial damage in the Fas pathway of apoptosis. Cell. 1998;94:491-501.

[62] Degenhardt K, Sundararajan R, Lindsten T, Thompson C, White E. Bax and Bak independently promote cytochrome c release from mitochondria. J Biol Chem. 2002;277:1412714134.

[63] Wang W, Adachi M, Kawamura R, Sakamoto H, Hayashi T, Ishida T, Imai K, Shinomura Y. Parthenolide-induced apoptosis in multiple myeloma cells involves reactive oxygen species generation and cell sensitivity depends on catalase activity. Apoptosis. 2006;11:2225-2235.

[64] Zunino SJ, Ducore JM, Stroms DH. Parthenolide induces significant apoptosis and production of reactive oxygen species in high-risk pre-B leukemia cells. Cancer Lett. 2007;254:119127.

[65] Pajak B, Gajkowska B, Orzechowski A. Cycloheximidemediated sensitization to TNF- $\alpha$-induced apoptosis in human colorectal cancer cell line COLO 205; role of FLIP and metabolic inhibitors. $J$ Physiol Pharmacol. 2005;56:101-118.

[66] Suzuki A, Tsutomi Y, Akahane K, Araki T, Miura M. Resistance to Fas-mediated apoptosis activation of caspase 3 is regulated by cell cycle regulator p21WAF 1 and IAP gene family ILP. Oncogene. 1998;275:1129.

[67] Sah NK, Munshi A, Kurland JF, McDonnel TJ, Sul B, Meyn RE. Translation inhibitors sensitize prostate cancer cells to apoptosis induced by tumor necrosis factor-related apoptosisinducing ligand (TRAIL) by activating c-Jun N-terminal kinase. J Biol Chem. 2003;278:20593-20602.

[68] Yao H, Tang X, Shao X Feng L, Wu N, Yao K. Parthenolide protects human lens epithelial cells from oxidative stressinduced apoptosis via inhibition of activation of caspase-3 and caspase-9. Cell Res. 2007;17F:565-571.

[69] Guzman ML, Rossi RM, Karnischky L, Li X, Peterson DR, Howard DS, Jordan CT. The sesquiterpene lactone parthenolide induces apoptosis of human acute myelogenous leukemia stem and progenitor cells. Blood. 2005;105:4163-4169.

Submitted: 5 November, 2007 Accepted after reviews: 24 December, 2007 